\title{
Intelligence as Smart Heuristics
}

Markus Raab and Gerd Gigerenzer

Sonderdruck aus:

R. J. Sternberg \& J. E. Pretz (Eds.). (2005). Cognition \& Intelligence (pp. 188-207). Cambridge, UK: Cambridge University Press. 


\title{
Intelligence as Smart Heuristics
}

\author{
Markus Raab and Gerd Gigerenzer
}

"The great end of life is not knowledge but action."

Thomas H. Huxley (1825-1895)

Humans and other animals differ in the amount of intelligence ascribed to them or that can be tested. Observed behavior reflects the underlying cognitive abilities of the individual that are either thought of as a general device system or a system of more or less independent parts. On this continuum, the view of intelligence as fast and frugal heuristics orientates toward a concept that models intelligence as parts (tools) of a larger system (adaptive toolbox). This view departs from the notion of intelligence as an assembly of "factors": either one $(g)$, a few, or many. The idea that one could model the intelligence of a person by the values of one or several factors became prominent after the invention of factor analysis, a statistical tool, in the early twentieth century. A key problem with this tool-driven metaphor of intelligence is that it does not describe how cognition translates into behavior. The consequence of this missing link is that the usefulness of factor values to predict behavior is quite limited (Sternberg, Grigorenko, \& Bundy, 2001). More importantly, the exclusive focus on paper-and-pencil tasks has estranged the notion of intelligence from the abilities and heuristics that are relevant for everyday behavior as well as for solving the problems that experts struggle with.

In this chapter, we propose a radically different view of intelligence that links cognition with behavior in terms of heuristics. A heuristic is a mental device that can solve a class of problems in situations with limited knowledge and time. Unlike an IQ value or a set of values on several intelligence factors, models of heuristics describe mechanisms or processes with which people solve problems. Because there are many classes of problems that confront humans, there are many heuristics, each one adapted to a specific class. However, these heuristics are composed of a smaller number of building blocks, the set of which we call the adaptive 
toolbox. The relation between heuristics and building blocks is analogous to the relation between chemical elements and subatomic particles: There are many heuristics, just as there are a large number of elements, but they are made of only a few building blocks, such as protons and electrons.

The vision of intelligence as an adaptive toolbox embodies an ecological and social view of rationality, not a logical one. The goal of the research program is (a) to describe the building blocks and heuristics, that is, the content of the adaptive toolbox; (b) to describe the problem structures or environments in which various heuristics can be successful, that is, the ecological rationality of heuristics; and (c) to determine individual differences in the use of heuristics. The program is outlined in Gigerenzer, Todd and the ABC Research Group (1999) and Gigerenzer and Selten (2001) and has its intellectual roots in the work of Herbert Simon (e.g., 1955, 1956) on bounded rationality. Let us start with three illustrative examples of heuristics.

\section{Recognition Heuristic}

Imagine you are a contestant in the show "Who Wants to Be a Millionaire" and face the one-million-dollar question: "Which city has a larger population: San Diego or San Antonio?" If you are as knowledgeable as a group of undergraduates at the University of Chicago, then your chance of winning is not bad: Almost two-thirds of them got the answer right - San Diego. What, however, if you had as little knowledge as a group of German students, who knew scarcely anything about San Diego and had mostly not even heard of San Antonio? When a dozen Germans answered this question, $100 \%$ got the answer right (Goldstein \& Gigerenzer, 2002). How can it be that people who know less about a subject nevertheless make more correct inferences? The answer is that the Germans used a smart heuristic, the recognition heuristic: If you have heard of one city (San Diego) but not the other (San Antonio), infer that the one you recognize by name has the larger population. Note that the Americans could not use this heuristic because they knew too much; they had heard of both cities. The recognition heuristic can be used by people who are partially ignorant, that is, have heard of one but not the other alternative. When British soccer fans want to predict the winner of Manchester United playing Shrewsbury Town, they cannot use the recognition heuristic because they recognize both names, but most Americans know immediately who will win the game. In fact, when Turkish students predicted the outcomes of all the English F.A. Cup third-round soccer games, they followed the recognition heuristic in $95 \%$ (627 out of 662) of the cases where they recognized only one of the team's names, and were nearly as accurate as the highly informed British group (Ayton \& Önkal, 1997). 
Note that the point is not that less knowledge is always better. The point is that we are regularly in situations where we have limited knowledge, and in these situations the recognition heuristic is a smart mind tool for extracting information from ignorance. Note also that the Americans, Germans, British, and Turkish students in these experiments may have a range of IQs, but an IQ does not describe how one solves a problem, nor can the variability in IQs predict the counterintuitive results.

For the general task of inferring which of two objects scores higher on a criterion, the recognition heuristic can be defined as the following: If one of two objects is recognized and the other is not, then infer that the recognized object has the higher value.

The heuristic does not always guarantee the making of good inferences; its success depends on the problem structure, or the structure of the environment. The recognition heuristic is successful when recognition is informative, that is, not random, but positively correlated with the criterion.

The recognition heuristic guides a broad range of behaviors, from selecting brands in the supermarket, buying CDs, and watching movies, to food and habitat choice. People who use the recognition heuristic show two kinds of counterintuitive behavior. First, the recognition heuristic searches only for recognition information, not for recall information, and thus tends to ignore information concerning the recognized object. For instance, Goldstein and Gigerenzer (2002) taught American students a powerful cue for predicting the population of German cities: whether or not a city has a soccer team in the major league. After the training session, the participants (who only learned about soccer teams, whereas the predictive power of name recognition was never mentioned) were tested on critical pairs: one city that they recognized from before the experiment but they had now learned has no soccer team (such as Hanover), and one city that they did not recognize (such as Bielefeld). Participants knew that all cities were among the largest in terms of population. Despite being trained on soccer team information, more than $90 \%$ of the participants inferred that the city they recognized had the larger population, thus ignoring the soccer team cue. There is comparative evidence in animals that recognition dominates competing information. For instance, when wild Norway rats choose between two foods, one that they recognize from the breath of a fellow rat and one that they do not recognize, they tend to choose the recognized one, even if the fellow rat is (experimentally made) sick at the time (Galef, 1987; Galef, McQuoid, \& Whiskin, 1990).

The second counterintuitive prediction is the less-is-more effect (Gigerenzer \& Goldstein, 1999). A less-is-more effect occurs when less knowledge leads, with the help of the recognition heuristic, to better inferences than more knowledge would have done. The San Diego question illustrates this effect. Since the recognition heuristic can be easily formalized, one can predict exactly when the less-is-more effect will occur and 
when it will not. Individual differences in recognition are of utmost importance for these predictions. For instance, when about half of the objects (such as sports teams or stocks) are recognized, then the chances for the less-is-more effect are best.

The recognition heuristic is not the only case where wisdom can emerge from the poorly informed mind. An interesting variant is the situation in which collective wisdom emerges from the poorly informed masses, in honey bees (Seeley \& Buhrmann, 2001) as well as in humans. Let us return to "Who Wants to be a Millionaire." You are trying to decide whether Nashville or Knoxville is the capital of Tennessee and you have no idea, but you can appeal to two outside sources for help. You can call the smartest person you know, or you can ask the audience to vote. So whom would you chose: your brainy brother-in-law or a random bunch of loafers who have nothing better to do on a weekday afternoon than sit in a TV studio? The friend gets it right two-thirds of the time, but the audience nine times out of ten. Similarly, when experts predicted that the influx of inexperienced investors would create a situation that the stock market would not be able to absorb, that situation did not happen. The market is smart even when the people within it are dumb.

\section{Gaze Heuristic}

Imagine you want to build a robot that can catch balls to play baseball, for instance. (It's a thought experiment - no such robots yet exist.) If you follow a classical artificial intelligence (AI) approach, you will aim to give your robot a complete representation of its environment and the most sophisticated computational machinery. First, you might feed your robot the family of parabolas (because thrown balls have parabolic trajectories). In order to choose the right parabola, the robot needs instruments that can measure the ball's initial distance, its initial velocity, and its projection angle. But in the real world, balls do not fly in true parabolas because of air resistance and wind. Thus, the robot would need additional instruments to measure the wind speed and direction at each point on the ball's flight and compute the resulting path. A true challenge. And there is more: spin and myriad other factors that the robot would have to measure and incorporate into a complete representation.

There is, however, an alternative strategy that does not aim at complete information and representation, but rather at smart heuristics. One method to discover such heuristics is to study actual players. McLeod and Dienes (1996) discovered that experienced players use a simple heuristic, which is the gaze heuristic. When a ball comes in high, the player fixates on the ball and starts running. The heuristic is to adjust the running speed so that the angle of gaze, that is, the angle between the eye and the ball, remains constant (or within a certain range). In our thought experiment, 
a robot that uses this heuristic does not need to measure wind, air resistance, spin, or the other causal variables. It can get away with ignoring this information. All the relevant information is contained in one variable: the angle of gaze. Attending to this one variable alone and ignoring all causal relevant variables is an example of a class of decision rules that are known as one-reason decision making.

Note that the gaze heuristic achieves its goal by transforming the relationship between the eyes of the player and the relevant part of the environment, the moving ball, into a linear line. Like all heuristics, the gaze heuristic is domain-specific, because it can only be used when balls come in high and therefore an angle of gaze exists. Imagine catching a ball as a baseball catcher. Unlike the outfielder, who can use the angle of gaze to catch the flying ball, the catcher is frontally approached by the ball. However, he can use the time-to-contact heuristic that looks for retinal image information (search rule) to estimate the time to collision between ball and hand (Hubbard \& Seng, 1954). And indeed people mainly use the change in size of the approaching baseball (stopping rule; no further information such as background information is used) to estimate the time when the ball will collide (e.g., Savelsbergh, Whiting, \& Bootsma, 1991). Therefore, players preplan their movement (decision rule) on one information source. Pigeons also use this type of information, although not to collide but to avoid collision in the air. This time-to-contact information can be tracked down to the level of neurons (Wang \& Frost, 1992), and serves as a prototype example of how mechanisms for even more complex behavior can be described on a low level. Just like the recognition heuristic, the gaze heuristic and the time-to-contact heuristic search only for one piece of information and ignore the rest.

\section{Tit-for-Tat Heuristic}

Let us now turn to social intelligence. Two people play a game: Each has two behavioral options, to cooperate with the other, or to "defect." If one cooperates and the other defects, the first is exploited by the second, a situation that can be represented in monetary terms, for example, by stating that the first loses $\$ 1$ whereas the second gains $\$ 3$. If neither cooperates, nobody loses and nobody gains anything. If both cooperate, each gains $\$ 2$. Such a situation is known as the prisoner's dilemma. Standard rational choice theory says that the optimal behavior is for both sides to defect, because whatever the other person does, it is always an advantage to defect. There is, however, a fast and frugal heuristic called tit-for-tat that can outperform the "optimal" strategy. In the first round, tit-for-tat always cooperates, that is, it trusts the partner. Thereafter it searches in memory for the partner's response (search rule), memorizes only the last move of the partner (stopping rule), and reciprocates, that is, imitates the partner's 
behavior (decision rule). In a famous tournament, Axelrod (1984) showed that tit-for-tat outperformed highly sophisticated strategies that analyzed more information about the partner's moves and based their behavior on heavy computational machinery.

Tit-for-tat is a social exchange heuristic that can perform well in environments where other tit-for-tat players exist. It illustrates how simplicity and transparency can lead to highly efficient social behaviors. Together with other social heuristics, such as searching for information that could detect cheaters in social contracts (Cosmides \& Tooby, 1992), the view of social intelligence as part of the adaptive toolbox provides, in our opinion, a better basis for understanding the nature of social intelligence than the current program of quantifying social and emotional intelligence by questionnaires and factor values (Gigerenzer, 2000).

\section{THE ADAPTIVE TOOLBOX}

These three heuristics and their building blocks illustrate some of the mental tools that underlie intelligent behavior, both social and nonsocial. The adaptive toolbox is, in two respects, a Darwinian metaphor for intelligence. First, evolution does not follow a grand plan, but results in a patchwork of solutions for specific problems. The same holds true for the toolbox: Its heuristics are domain-specific, not general. Second, the heuristics in the adaptive toolbox are not intrinsically good or bad, rational or irrational, but only relative to an environment, just as adaptations are context-bound. In these two restrictions lies their potential: Heuristics can perform astonishingly well when used in a suitable environment. The rationality of the adaptive toolbox is not logical, but rather ecological. In the context of the toolbox, "adaptive" refers to the cognitive abilities that allow us to perform well in our particular (past) environments.

\section{Ecological Rationality}

Herbert Simon once compared bounded rationality, that is, intelligent behavior under conditions of limited time and knowledge, to a pair of scissors. One blade is cognition, the other the environment. If one looks at just a single blade, one will not understand how human intelligence works. A football coach who constantly ignores the opponents' line-up when defining the strategy of his own team's attacks will sooner or later be fired. In other words, the structure of the environment and the cognitive heuristics have to match. Putting two knives together, however, does not make a pair of scissors; a heuristic such as divide and conquer can only solve complicated problems if they can be decomposed. Fast and frugal heuristics are domain-specific; they succeed in one environment but may fail in another. Computer simulations and mathematical proofs have given us a better 
understanding of the environmental structures in which specific heuristics operate (Gigerenzer et al., 1999; Martignon \& Hoffrage, 2002; Payne, Bettman, \& Johnson, 1993). This work has shown that many fast and frugal heuristics, like tit-for-tat, can match or even outperform more complex statistical models in situations ranging from medical decision making to investment choice.

Intelligent behavior needs to satisfy important constraints other than finding the best behavior, including being able to act fast and on the basis of incomplete information. A cartoon illustrates this point. An early Homo sapiens is standing in front of a cave, facing a lion. Our ancestor is calculating the trajectory of the jump and the magnitude of the impulse a lion will have in order to decide what to do. The last picture shows a sated, happy lion. The cartoon makes us smile because its message conflicts with our superego of rational decision making, which demands: Search through all the available information, deduce all the possible consequences, and compute the optimal decision. Intelligent decision making, from this point of view, is based on the ideals of omniscience and optimization. An organism aiming for these heavenly ideals, however, might not survive on Earth. Nevertheless, the majority of rational decision making models in the social, behavioral, and cognitive sciences, as well as in economics, rely on some version of this doctrine. Even when empirical studies show that real human beings cannot live up to it, the doctrine is not abandoned as other models would be, but is instead retained and declared a norm, that is, how we should reason. The concept of ecological rationality, however, clarifies that intelligent behavior can be achieved by smart heuristics applied to the proper situations, and that it does not need the fiction of a superintelligence.

\section{Building Blocks}

Heuristics, such as the recognition, gaze, and tit-for-tat heuristic, are composed of building blocks. The most important ones are search rules, stopping rules, and decision rules.

\section{Search Rules}

There are two kinds of search that intelligent behavior requires: search for alternatives and search for cues. In game shows such as Millionaire, the alternatives are fixed, and one has to search for cues to decide what the correct answer is. Mere name recognition is a minimal cue. When both alternatives are recognized, then the search for cues in memory or in external sources, such as the Internet or a good friend, can be guided by a number of search rules. Search randomly is the most simple rule; try the cues with the highest validity first is a more promising one (Gigerenzer \& Goldstein, 1999). When the alternatives are not known or not fixed a priori, 
then intelligent behavior has to employ search rules for alternatives. When searching for houses or potential spouses, search can again be more or less random, that is, one happens to encounter possible objects or persons without taking measures that the better options tend to come first, or it can be structured, as in traditional societies where parents, matchmakers, or horoscopes guide the search.

\section{Stopping Rules}

Search for cues or alternatives must be stopped at some point. Classical models of optimal search assume that there is a way to compute the optimal stopping point, that is, where the costs of further search exceed its benefits. In the real world, however, such cost-benefit trade-offs are rarely knowable and predictable. Heuristics employ search rules that stop search without explicit cost-benefit computations. For instance, the recognition heuristic stops the search when it has recognized one alternative but not the other. It does not proceed and look up information about the recognized object. In Simon's satisfying heuristic, the search for alternatives (e.g., houses or potential spouses) is stopped when the first alternative that meets a specific aspiration level is encountered (Simon, 1955). If search takes too long, for instance, because the aspiration level of a person is too high, then the aspiration level itself can be lowered (Selten, 2001). More effectively than cognitive rules, emotions such as love can also stop the search, enabling commitment to the loved one.

\section{Decision Rules}

A decision rule describes how a decision is made after the search has been stopped. Decision rules define how the information searched and found is used to make a decision. Psychology has a tradition of assuming that intelligent behavior implies weighting and combining cues (e.g., multiple linear regression models), but the research on fast and frugal heuristics has shown that less is often more. The recognition heuristic, the gaze heuristic, and tit-for-tat all employ one-reason decision making, because they rely on only one cue to make the decision and ignore all others.

\section{Domain-Specificity of Heuristics}

The heuristics in the adaptive toolbox are domain-specific cognitive abilities. As mentioned before, the domain-specificity of the heuristics is more expressed than that of their building blocks, just as chemical elements are quite distinct and show different processes, yet, as far as we know, consist of the same particles. Thus, domain-specificity must be discussed relative to the level of analysis. The domain definition seems very crucial to determining the specificity of the tools in the toolbox. For instance, eyes may be domain-specific in the sense that they process visual but not acoustic 
information. On the other hand, we do not have different eyes for different perceptual abilities, such as for locating objects in space or detecting features of objects. However, we know from different locations within the visual cortex that they are specialized to detect the color, shape, or direction of a moving object. Similarly, the same heuristic may be used in different environments. The process that activates the use of one heuristic over another is not well understood today.

At least four arguments favor a domain-specific intelligence that works with fast and frugal heuristics. First, much of intelligence involves going beyond the information given, that is, to make reasonable inferences. Although there are powerful statistical tools for induction, no single statistical method works in every environment (Gigerenzer et al., 1989). In addition, our own intuition tells us that we are often capable of producing smart solutions in one domain but quite stupid ones in another. Second, a general purpose mechanism would run into the well-known problem of computational explosion; that is, even if it were known, it could not work. Even for well-defined problems such as chess, there is no optimal algorithm known, and experts, just like Deep Blue, have to rely on heuristics. This indicates that general purpose notions such as the $g$ factor for intelligence (Jensen, 1998) are doomed to fail in the face of computational complexity. Third, the lesson artificial intelligence designers had to learn when they actually tried to build robots was similar: A general inference machine was not feasible, and designers opted for a number of modules that practiced and orchestrated division of labor, as do the organs in our bodies or a symphony orchestra. The more general an intelligence is, the slower it becomes. Fourth, human intelligence has to achieve more than correct answers to a test, as is obvious when we come to social or emotional intelligence. Domain-specific intelligence can be modeled by modularity of the tools in the adaptive toolbox. The term modular or module has multiple meanings, from Fodor's (1987) ideas that modules consist of the senses plus language, to the evolutionary-based idea that a module is an array of sensory, cognitive, and emotional tools designed to solve important adaptive tasks such as raising children, finding food, and avoiding predators (e.g., Cosmides \& Tooby, 1992). The example of catching a ball makes it plausible to argue for sensory intelligence and motor modules (see Hossner, 1995; Keele, Jennings, et al., 1995). The modularity hypothesis of social intelligence postulates that modules draw on a number of heuristics as tools and are hierarchically organized (see Gigerenzer, 2000, for a detailed argumentation). In addition, it is plausible to assume that cognitive modules have less hard-wired properties than sensory and motor modules. For instance, the distinction between different sensors and different effectors is easily defined, and concepts such as equilibrium sense can be tracked down to modular entities because of this specific neuronal architecture. Even with the new power of techniques in neuroscience, however, 
precisely locating the specific networks that are active for cognitive or social problems still seems far away. Due to the less restricted array of modules for cognitive abilities, the modularization is even more interwoven with the environmental system that humans confront.

\section{Social Intelligence}

Homo sapiens is one of the few species where genetically unrelated members cooperate in certain tasks. Social intelligence, that is, the ability to handle interactions with others intelligently, has consequently been proposed as the hallmark of human intelligence and one of the defining features of Homo sapiens, together with profound tool use and language. Nevertheless, it is far from clear exactly what entails social intelligence or Machiavellian intelligence, its exploitive sibling. Again, we argue that the way to find out about social intelligence is to discover and model the actual mechanisms, that is, the heuristics people use when dealing with others. We believe that this is far superior to asking people to answer a questionnaire and to giving them values on "factors" of social intelligence, or a quotient of emotional intelligence. With these numbers, just as with standard intelligence tests, one will never discover what people do when they try to handle others.

The framework of the adaptive toolbox can be applied to unravel social intelligence (Gigerenzer, 1997; Miller \& Todd, 1998). This provides precise models and a modular perspective that has different degrees of generality: The building blocks of social intelligence will be fewer but more general than the social heuristics themselves. Table 1 lists examples of social and nonsocial heuristics, their building blocks, and applications.

Tit-for-tat, which we discussed earlier, is a fast and frugal social heuristic. It can handle social exchange situations, such as asking someone for help and offering something in return. There are numerous candidates for social heuristics and building blocks, but they are typically not as clearly defined as tit-for-tat. These include forms of social imitation, known as follow the crowd (Boyd \& Richerson, 2001; Marsh, 2002). The advantage of such imitation behavior is well understood in animals, for example, in schools of fish (Laland, 2001; Williams, 1996). Growing evidence from a variety of other human imitation behaviors, from childhood to panic behaviors, shows how social imitation can be defined in each context in a variety of domains (Noble \& Todd, 2002). Social categorization heuristics, such as judgments about others that either are within the same group (ingroup) or from another group (outgroup), seem to be the rule rather than the exception. The heuristic that a person from the same group is a "good person," and that their information or judgments are accurate, enables fast decisions about a topic based on other persons' information or judgments. 
TABLE 1. Examples of Social and Nonsocial Heuristics, Their Building Blocks, and Applications

\begin{tabular}{|c|c|c|}
\hline Heuristic & Building Blocks & Applications \\
\hline $\begin{array}{l}\text { Recognition } \\
\text { Heuristic }\end{array}$ & $\begin{array}{l}\text { Search rule: Look for recognition } \\
\text { information } \\
\text { Stopping rule: If you recognize one } \\
\text { option and not the other, stop } \\
\text { search } \\
\text { Decision rule: Infer that the option you } \\
\text { recognize has the higher value on } \\
\text { the criterion }\end{array}$ & $\begin{array}{l}\text { Answering general } \\
\text { knowledge questions; } \\
\text { predicting outcomes of } \\
\text { sports games (Goldstein } \\
\text { \& Gigerenzer, 2002); } \\
\text { investment decisions; } \\
\text { stock picking (Borges } \\
\text { et al., 1999) }\end{array}$ \\
\hline $\begin{array}{l}\text { Gaze } \\
\text { Heuristic }\end{array}$ & $\begin{array}{l}\text { Fixate the ball and start running, } \\
\text { thereafter: } \\
\text { Search rule: Look for information } \\
\text { concerning the angle of gaze } \\
\text { Stopping rule: Use the angle of gaze } \\
\text { only } \\
\text { Decision rule: When the angle } \\
\text { changes, adjust speed so that the } \\
\text { angle remains constant }\end{array}$ & $\begin{array}{l}\text { Catching balls that come in } \\
\text { high, as in baseball and } \\
\text { cricket (McLeod \& } \\
\text { Dienes, 1996); avoiding } \\
\text { collision in flight; } \\
\text { avoiding collisions in } \\
\text { sailing }\end{array}$ \\
\hline $\begin{array}{l}\text { Tit-for-Tat } \\
\text { Heuristic }\end{array}$ & $\begin{array}{l}\text { Trust first, thereafter: } \\
\text { Search rule: Recall information } \\
\text { concerning the behavior } \\
\text { (cooperation or defection) of your } \\
\text { partner } \\
\text { Stopping rule: Ignore everything } \\
\text { except the last behavior of your } \\
\text { partner } \\
\text { Decision rule: Imitate the behavior of } \\
\text { your partner }\end{array}$ & $\begin{array}{l}\text { Exchange of goods; } \\
\text { international politics; } \\
\text { social behavior and trust } \\
\text { in dyadic relations } \\
\text { (Kollock, 1994; Messick } \\
\text { \& Liebrand, 1995) }\end{array}$ \\
\hline $\begin{array}{l}\text { Take-the- } \\
\text { First } \\
\text { Heuristic }\end{array}$ & $\begin{array}{l}\text { Search rule: Generate options in the } \\
\text { order of validity } \\
\text { Stopping rule: Stop after the first } \\
\text { option is generated that can be } \\
\text { implemented, ignore all the rest } \\
\text { Decision rule: Take this option }\end{array}$ & $\begin{array}{l}\text { Chess playing (Klein et al., } \\
\text { 1995); allocation } \\
\text { decisions in ball games }\end{array}$ \\
\hline $\begin{array}{l}\text { Take-the- } \\
\text { Best } \\
\text { Heuristic }\end{array}$ & $\begin{array}{l}\text { Search rule: First try the recognition } \\
\text { heuristic; if both objects are } \\
\text { recognized, look up cues in order } \\
\text { of their validity } \\
\text { Stopping rule: Stop search when the } \\
\text { first cue is found that has a positive } \\
\text { value for one alternative, but not } \\
\text { for the other } \\
\text { Decision rule: Infer that the alternative } \\
\text { with the positive cue value has the }\end{array}$ & $\begin{array}{l}\text { Hindsight bias (Hoffrage, } \\
\text { Hertwig, \& Gigerenzer, } \\
\text { 2000); attractiveness } \\
\text { judgments of famous } \\
\text { men or women; } \\
\text { predicting high school } \\
\text { dropout rates; } \\
\text { homelessness rates; } \\
\text { (Czerlinski, Gigerenzer, } \\
\text { \& Goldstein, 1999) }\end{array}$ \\
\hline
\end{tabular}


Again, the specific description of this ingroup-outgroup heuristic is lacking. Is the information from ingroup members just weighted higher than the information from outgroup members, or does it dominate the other information, just as recognition information dominates competing information? We do not know these details, but it seems possible to experimentally test the different ways of how such social heuristics work, once they are precisely formulated. From our standpoint, the starting point is set; that is, we do not expect to find only one general purpose tool, but rather several heuristics for social intelligence. This also has methodological and practical consequences. For instance, if no such general social intelligence exists, there is no point in developing and measuring with a one-dimensional social intelligence test or using a single observation, scale, or another method to detect social intelligence. On the other hand, the modular perspective needs to define a research agenda of how to find proposed heuristics of social intelligence, and how to define environments in which specific heuristics do and do not work, and we are just starting this adventure. We do have proposals: modules for social contracts, threats, precautions, as well as cheating mechanisms (Cosmides, 1989; Gigerenzer \& Hug, 1992; Kummer et al., 1997).

\section{Nonsocial Intelligence}

Imagine that you are attending a conference and wish to buy a new laser pointer in your free time. The first shop you encounter has two special offers near the entrance. The recognition heuristics would assume that if you recognize one company label (e.g., Sony) and not the other, the Sony laser pointer will be chosen. However, if it happens that both are from Sony, you may continue searching for more information such as the price or size, until you find a difference that favors one laser pointer over the other. A fast and frugal heuristic take-the-best can describe this behavior (Gigerenzer \& Goldstein, 1999). The heuristic is called take-the-best because it takes the option based on the first cue that favors one option over the other and ignores all other available information. Take-the-best consists of three buildings blocks: rules for searching, stopping, and making a decision. Search for cues is in the order of cue validities (search rule). These validities, which are based on the relative frequency with which a cue predicts the criterion, can be acquired by individual or social learning, or, in the case of some animal species, such as female guppies with regard to mate choice, seem to be genetically coded (Dugatkin, 1996). Search is stopped when the first cue is found on which the two alternatives differ (stopping rule). The alternative with the positive cue value (e.g., lower price, smaller size of the laser pointer) is chosen (decision rule). In experiments conducted by Newell et al. (2004), the searching, stopping, and decision rules of 
take-the-best are followed in $75 \%$ to $92 \%$ of all cases (see also Bröder, 2000, 2003; Newell \& Shanks, 2003).

In this chapter, we have seen evidence that less information can result in better performance. Whereas the recognition heuristic and the take-thebest heuristic describe how to choose between given alternatives, the takethe-first heuristic describes how people generate alternatives from their memory. For instance, in chess it is known that experts can generate a large number of options, but that the first ones generated are often the best options (Klein et al., 1995). Take-the-first describes how options are generated from the memory (Johnson \& Raab, 2003). The options are generated by order of their appropriateness in a specific situation. Like take-the-best (where cues are searched for in order of cue validity), take-the-first looks up alternative options by option validity (search rule). In familiar, yet illdefined tasks, take-the-first chooses one of the initial options, once a goal and strategy have been defined. When generating options in sports, experts generate only a few options (stopping rule) and decide predominantly on the first option that can be implemented (decision rule). Limited search and quick stopping can be beneficial: Experts are not only faster but also more accurate with this fast heuristic, compared to making the choice after generating and giving due consideration to all possible alternatives. For instance, Johnson and Raab (2003) showed experienced handball players a 10-second video sequence from a game, then froze the video and asked the players what option they would take, such as pass right, pass left, or throw at the goal. The results indicated that these players searched for options in order of their appropriateness, generated only a few options, and picked mostly one of the first that was generated. In contrast, when they were asked to generate all possible options and then, after reflection, to pick the one that seemed best, their choices were no longer as appropriate as when they spontaneously picked the first good one that came to mind.

\section{Ecological Rationality}

Domain-specific heuristics are designed to work in specific environments. Therefore it is natural that they may not work equally well in another environment. Table 2 gives examples of heuristics and specific environments in which these heuristics fail or succeed. For instance, the recognition heuristic can only be used in situations with partial ignorance, that is, when one object is recognized and the other is not. Using this heuristic is ecologically rational to the degree that recognition is correlated with the criterion; when such a correlation does not exist, it is no longer a promising strategy (although it may not hurt). For instance, although brand-name recognition is typically correlated with quality, firms that invest their money in advertisement that does not give information about the product, but is only intended to increase name recognition, can exploit people's reliance on the 
TABLE 2. Fast and Frugal Heuristics and Examples for Environmental Structures that Enable Good or Poor Performance

\begin{tabular}{|c|c|c|}
\hline Heuristics & $\begin{array}{l}\text { Environments that Enable } \\
\text { Good Performance }\end{array}$ & $\begin{array}{l}\text { Environments that Enable } \\
\text { Poor Performance }\end{array}$ \\
\hline $\begin{array}{l}\text { Recognition } \\
\text { Heuristic }\end{array}$ & $\begin{array}{l}\text { Positive correlation between } \\
\text { recognition and criterion }\end{array}$ & $\begin{array}{l}\text { Zero correlation between } \\
\text { recognition and criterion }\end{array}$ \\
\hline $\begin{array}{l}\text { Gaze } \\
\text { Heuristic }\end{array}$ & $\begin{array}{l}\text { Intersection of moving objects } \\
\text { for which the angle of gaze } \\
\text { changes (relative to a fixed } \\
\text { observer) }\end{array}$ & $\begin{array}{l}\text { Intersection of moving } \\
\text { objects for which the angle } \\
\text { of gaze is constant (relative } \\
\text { to a fixed observer) }\end{array}$ \\
\hline $\begin{array}{l}\text { Tit-for-Tat } \\
\text { Heuristic }\end{array}$ & $\begin{array}{l}\text { Mostly tit-for-tat players } \\
\text { present; the possibility to } \\
\text { exclude noncooperative } \\
\text { players by custom or law } \\
\text { (Dawkins, 1989; Boyd \& } \\
\text { Lorberbaum, 1987) }\end{array}$ & Only defectors present \\
\hline $\begin{array}{l}\text { Take-the-First } \\
\text { Heuristic }\end{array}$ & $\begin{array}{l}\text { An environment in which the } \\
\text { person is highly trained by } \\
\text { feedback, that is, options are } \\
\text { automatically generated from } \\
\text { memory in the order of } \\
\text { validity }\end{array}$ & $\begin{array}{l}\text { An environment in which the } \\
\text { person is a novice, that is, } \\
\text { options are not generated } \\
\text { in the order of validity }\end{array}$ \\
\hline $\begin{array}{c}\text { Take-the-Best } \\
\text { Heuristic }\end{array}$ & $\begin{array}{l}\text { Noncompensatory } \\
\text { environments, in which } \\
\text { higher-ranking cues cannot be } \\
\text { compensated by combinations } \\
\text { of lower-ranking cues } \\
\text { (Martignon \& Hoffrage, 1999) }\end{array}$ & $\begin{array}{l}\text { Compensatory environments, } \\
\text { in which higher-ranking } \\
\text { cues can be compensated } \\
\text { by combinations of } \\
\text { lower-ranking cues }\end{array}$ \\
\hline
\end{tabular}

recognition heuristic. In an international study of stock picking, the recognition heuristic - based on laypeople's name recognition - outperformed the level of major mutual funds and the market (Borges et al., 1999). The take-the-first heuristic works quite well for experts (e.g., chess masters). However, on the assumption that novices do not have the experience to generate options automatically in order of their appropriateness, take-thefirst would not be advantageous at this low level of knowledge.

\section{RELATION TO OTHER APPROACHES}

The view of intelligence as an adaptive toolbox with smart heuristics is not a minor variation of the existing theories of intelligence, but represents a radical break with several entrenched ideas. First and most important, all theories that try to capture the nature of intelligence in terms of factor values - one, a few, or many - follow an entirely different conception of 
intelligence. If one thinks of intelligence as an interaction between the mind and the world, then one needs to model exactly this, and this is what models of heuristics are all about. Factor values are mute about the mechanisms of this interaction. Second, all theories - differential approaches, information processing approaches, and componential approaches (see Sternberg \& Kaufman, 2002) - that look at only one blade of Simon's pair of scissors (the cognitive abilities), at the price of ignoring the other blade (the structure of the environment), are hardly compatible with the present approach. Third, approaches that incorporate cognitive abilities and the environment but ignore the domain-specificity (e.g., the person-situation interaction theory of Snow, 1994) can be distinguished from our approach. Fourth, many approaches ignore the evolutionary perspective on intelligence (for examples, see Sternberg, 1999).

\section{Frames of Mind and Multiple Intelligences}

Gardner (1983) argues that the notion of relative autonomous cognitive abilities ("multiple intelligences" in his concept) is relevant to understanding the specialized performance of humans in many domains. This domainspecificity is similar to the view of intelligence as smart cognitive heuristics, but with two important differences. First, Gardner's multiple intelligences (e.g., linguistic, spatial, or musical intelligence) are, like most approaches, still partly based on psychometric data. Specifically, the absence of correlations such as those between spatial and verbal abilities (Gardner, Kornhuber, \& Wake, 1996) as well as studies from specific populations (e.g., brain-damaged patients, low IQ savants) supports his view of multiple independent intelligences. According to this view, a person can be ascribed high or low musical intelligence, but the heuristics that people actually use when making music, such as how to practice, how to overcome a block or stage fright, how to perform and electrify the audience, and where to find inspiration for composing are not explicated. Second, an evolutionary view on domain-specificity results in important adaptive tasks (e.g., handling social contracts), although not in domains such as Gardner's musical or mathematical intelligences, which seem to be more motivated by university curricula.

\section{The Mind as a Swiss Army Knife}

A conception that is a close relative of the view of intelligence as an adaptive toolbox is the modular perspective of intelligence by Cosmides and Tooby (2002). The authors separate dedicated intelligence (systems or programs that are designed for solving a target set of adaptive computational problems) from improvisational intelligence (components that are designed to 
exploit transient or novel local conditions to achieve adaptive outcomes). The image of the mind as a Swiss Army knife stresses the idea that the mind holds domain-specific rather than general purpose tools. Like the adaptive toolbox, the Swiss Army knife view of intelligence is not based on the factor analysis analogy of mind, but on the actual processes needed to solve important adaptive problems and their modern equivalent. More so than the Swiss Army knife analogy, the concept of the adaptive toolbox brings the possibility for novel combinations of building blocks and nesting heuristics into the foreground. Most important, however, are the models of heuristics and building blocks (Gigerenzer \& Selten, 2001; Gigerenzer et al., 1999) that can flesh out the nature of the "Darwinian algorithms" and allow new and sometimes counterintuitive predictions to be deduced.

\section{PROGRAM REVIEW AND FUTURE}

To learn more about the view outlined in this chapter, we recommend Gigerenzer, Todd, and the ABC Research Group (1999). Briefly stated, the research program starts with computational models of heuristic candidates in a specific domain, analyzes the environmental structure of this domain, tests the heuristics in real-world environments by means of simulation, and tests whether and when people use these heuristics by means of experiment. This procedure can be varied to the specific problem on hand. Individual differences in the use of heuristics have been documented in a number of situations (e.g., Goldstein \& Gigerenzer, 2002; Rieskamp \& Hoffrage, 1999).

We would now like to highlight two routes into the future of the program. First, in the beginning of this chapter we extended the notion of cognitive modules to lower-level systems, such as the sensory and motor domains. This extension draws attention to the biological underpinnings of the candidate tools in a toolbox (Duchaine, Cosmides, \& Tooby, 2001). An example of this, as demonstrated in this chapter, is the ecological rationality perspective, in which evolutionary accounts may help us find the roots of the intelligent behavior observed nowadays.

Second, neuropsychological evidence may provide further insights into possible instantiations of proposed cognitive heuristics. At a minimum, neuropsychological evidence can help us understand whether different heuristics are biologically alike or different, both qualitatively and quantitatively. For quantitative differences we would expect activation quantity only in the same neuronal circuit, whereas for qualitative differences we would assume to see activation of different neuronal circuits. In addition, the arguments about the amount and kind of domain-specificity versus arguments about domain-generality can also be tested by comparing shared versus nonshared activation in different tasks of nested and nonnested heuristics. 
As with every perspective on intelligence, the adaptive toolbox will have its limits. Shepard (2001) speculated that fast and frugal heuristics reflect the nature of ordinary human intelligence, that is, the conscious and sometimes unconscious forms of reasoning and decision making in everyday life. Shepard believes that heuristics cannot do two things: describe the lower cognitive processes, such as those involved in perception, and describe those at the high-level end, the creative processes of scientific discovery. We do not know to what degree Shepard is right; we know of heuristics that work at the lower end, for example, the gaze heuristic and the time-to-contact heuristics. But many evolutionary hard-wired processes seem to need different kinds of models, such as the processes of face perception. The creative processes of artists and scientists are also mostly out of reach for modeling by fast and frugal heuristics, although one might add that they are out of reach of any theory. However, substantial evidence exists for a heuristic that describes the discovery of new theories in the cognitive sciences, the tools-to-theories heuristic (Gigerenzer, 2000).

The adaptive toolbox provides a research agenda of how to study cognitive abilities in terms of smart heuristics. At the same time, it provides an alternative to the notion of human intelligence driven by factor analysis, which bypasses the actual mechanisms with which humans make intelligent or less intelligent decisions.

\section{References}

Axelrod, R. M. (1984). The evolution of cooperation. New York: Basic Books.

Ayton, P., \& Önkal, D. (1997). Forecasting football fixtures: Confidence and judged proportion correct. Unpublished manuscript.

Borges, B., Goldstein, D. G., Ortmann, A., \& Gigerenzer, G. (1999). Can ignorance beat the stock market? In G. Gigerenzer, P. Todd, \& the ABC Research Group (Eds.), Simple heuristics that make us smart (pp. 59-74). New York: Oxford University Press.

Boyd, R., \& Lorberbaum, J. P. (1987). No pure strategy is evolutionary stable in the repeated prisoner's dilemma game. Nature, 327, 58-59.

Boyd, R., \& Richerson, P. J. (2001). Norms and bounded rationality. In G. Gigerenzer \& R. Selten (Eds.), Bounded rationality: The adaptive toolbox (pp. 281296). Cambridge, MA: MIT Press.

Bröder, A. (2000). Assessing the empirical validity of the "Take-the-Best" heuristic as a model of human probabilistic inference. Journal of Experimental Psychology: Learning, Memory, and Cognition, 26, 1332-1346.

Bröder, A. (2003). Decision making with the adaptive toolbox: Influence of environmental structure, intelligence, and working memory load. Journal of Experimental Psychology: Learning, Memory, and Cognition, 29, 611-625.

Cosmides, C. (1989). The logic of social exchange: Has natural selection shaped how humans reason? Studies with the Wason selection task. Cognition, 31, 187-276. 
Cosmides, C., \& Tooby, J. (1992). Cognitive adaptations for social exchange. In J. Barkow, L. Cosmides, \& J. Tooby (Eds.), The adapted mind: Evolutionary psychology and the generation of culture (pp. 163-228). New York: Oxford University Press.

Cosmides, C., \& Tooby, J. (2002). Unraveling the enigma of human intelligence: Evolutionary psychology and the multimodular mind. In R. J. Sternberg \& J. C. Kaufman (Eds.), The evolution of intelligence (pp. 145-198). Mahwah, NJ: Erlbaum.

Czerlinski, J., Gigerenzer, G., \& Goldstein, D. G. (1999). How good are simple heuristics? In G. Gigerenzer, P. Todd, \& ABC Research Group (Eds.), Simple heuristics that make us smart (pp. 97-118). New York: Oxford University Press.

Dawkins, R. (1989). The selfish gene. Oxford, UK: Oxford University Press.

Duchaine, B., Cosmides, L., \& Tooby, J. (2001). Evolutionary psychology and the brain. Current Opinion in Neurobiology, 11, 225-230.

Dugatkin, L. A. (1996). Interface between culturally based preferences and genetic preferences: Female mate choice in Poecilia Reticulata. Proceedings of the National Academy of Sciences, 93, 2770-2773.

Fodor, J. A. (1987). Modules, frames, frigeons, sleeping dogs, and the music of spheres. In J. R. Garfield (Ed.), Modularity in knowledge and representation and natural-language understanding (pp. 25-36). Cambridge, MA: MIT Press.

Galef, B. G., Jr. (1987). Social influences on the identification of toxic foods by Norway rats. Animal Learning \& Behavior, 15, 327-332.

Galef, B. G., Jr., McQuoid, L. M., \& Whiskin, E. E. (1990). Further evidence that Norway rats do not socially transmit learned aversions to toxic baits. Animal Learning \& Behavior, 18, 199-205.

Gardner, H. (1983). Frames of mind: The theory of multiple intelligences. New York: Basic Books.

Gardner, H., Kornhuber, M. L., \& Wake, W. K. (1996). Intelligence: Multiple perspectives. Fort Worth, TX: Harcourt Brace.

Gigerenzer, G. (1997). The modularity of social intelligence. In A. Whiten \& R. W. Byrne (Eds.), Machiavellian intelligence II (pp. 264-288). Cambridge, UK: Cambridge University Press.

Gigerenzer, G. (2000). Adaptive thinking: Rationality in the real world. Oxford, UK: Oxford University Press.

Gigerenzer, G., \& Goldstein, D. G. (1999). Betting on one good reason: The Take The Best heuristic. In G. Gigerenzer, P. M. Todd, \& ABC Research Group (Eds.), Simple heuristics that make us smart (pp. 75-95). New York: Oxford University Press.

Gigerenzer, G., \& Hug, K. (1992). Domain-specific reasoning: Social contracts, cheating, and perspective change. Cognition, 43, 127-171.

Gigerenzer, G., \& Selten, R. (2001). Rethinking rationality. In G. Gigerenzer \& R. Selten (Eds.), Bounded rationality: The adaptive toolbox (pp. 1-12). Cambridge, MA: MIT Press.

Gigerenzer, G., Swijtink, Z., Porter, T., Daston, L., Beatty, J., \& Krüger, L. (1989). The empire of chance. How probability changed science and everyday life. Cambridge, UK: Cambridge University Press.

Gigerenzer, G., Todd, P., \& ABC Research Group (1999). Simple heuristics that make us smart. New York: Oxford University Press.

Goldstein, D. G., \& Gigerenzer, G. (2002). Models of ecological rationality: The recognition heuristic. Psychological Review, 109, 75-90. 
Hoffrage, U., Hertwig, R., \& Gigerenzer, G. (2000). Hindsight bias: A by-product of knowledge updating? Journal of Experimental Psychology: Learning, Memory, and Cognition, 26, 566-581.

Hossner, E. J. (1995). Module der Motorik [Motor Modules]. Schorndorf, Germany: Hofmann.

Hubbard, A. W., \& Seng, S. N. (1954). Visual movements of batters. Research Quarterly of American Association of Health and Physical Education, 25, 42-57.

Jensen, A. R. (1998). The g factor. Westport, CT: Praeger.

Johnson, J., \& Raab, M. (2003). Take the first: Option generation and resulting choices. Organizational Behavior and Human Decision Processes, 91, 215-229.

Keele, S. W., Jennings, P., Jones, S., Caulton, D., \& Cohen, A. (1995). On the modularity of sequence representation. Journal of Motor Behavior, 27, 17-30.

Klein, G., Wolf, S., Militello, L., \& Zsambok, C. (1995). Characteristics of skilled option generation in chess. Organizational Behavior and Human Decision Processes, 62,63-69.

Kollock, P. (1994). The emergence of exchange structures: An experimental study of uncertainty, commitment, and trust. American Journal of Sociology, 100, 313345 .

Kummer, H., Daston, L., Gigerenzer, G., \& Silk, J. B. (1997). The social intelligence hypothesis. In P. Weingarten, S. D. Mitchell, P. J. Richardson, \& S. Maasen (Eds.), Human by nature: Between biology and the social sciences (pp. 157--179). Mahwah, NJ: Erlbaum.

Laland, K. N. (2001). Imitation, social learning, and preparedness as mechanisms of bounded rationality. In G. Gigerenzer \& R. Selten (Eds.), Bounded rationality: The adaptive toolbox (pp. 233-247). Cambridge, MA: MIT Press.

Marsh, B. (2002). Heuristics as social tools. New Ideas in Psychology, 20, 49-57.

Martignon, L., \& Hoffrage, U. (1999). Why does one-reason decision making work? A case study in ecological rationality. In G. Gigerenzer, P. Todd, \& the ABC Research Group, Simple heuristics that make us smart (pp. 119-140). New York: Oxford University Press.

Martignon, L., \& Hoffrage, U. (2002). Fast, frugal, and fit: Simple heuristics for paired comparisons. Theory and Decision, 52, 29-71.

McLeod, P., \& Dienes, Z. (1996). Do fielders know where to go to catch the ball or only how to get there? Journal of Experimental Psychology: Human Perception and Performance, 22, 531-543.

Messick, D. M., \& Liebrand, W. B. G. (1995). Individual heuristics and the dynamics of cooperation in large groups. Psychological Review, 102, 131-145.

Miller, G. F., \& Todd, P. M. (1998). Mate choice turns cognitive. Trends in Cognitive Sciences, 2, 190-198.

Newell, B., \& Shanks, D. R. (2003). Take-the-best or look at the rest? Factors influencing "one-reason" decision making. Journal of Experimental Psychology: Learning, Memory, and Cognition, 29, 53-65.

Newell, B., Rakow, T., Weston, N. J., \& Shanks, D. R. (2004). Search strategies in decision-making: The success of "success." Journal of Behavioral Decision Making, 17, 117-137.

Noble, J., \& Todd, P. M. (2002). Imitation or something simpler? Modelling simple mechanisms for social information processing. In K. Dautenhahn \& C. Nehaniv (Eds.), Imitation in animals and artifacts (pp. 423-440). Cambridge, MA: MIT Press. 
Payne, J. W., Bettman, J. R., \& Johnson, E. J. (1993). The adaptive decision maker. New York: Cambridge University Press.

Rieskamp, J., \& Hoffrage, U. (1999). When do people use simple heuristics and how can we tell? In G. Gigerenzer, P. Todd, \& the ABC Research Group (Eds.), Simple heuristics that make us smart (pp. 141-167). New York: Oxford University Press.

Savelsbergh, G. J. P., Whiting, H. T. A., \& Bootsma, R. J. (1991). Grasping tau. Journal of Experimental Psychology: Human Perception and Performance, 17, 315-322.

Seeley, T. D., \& Buhrmann, S. C. (2001). Nest-site selection in honey bees: How well do swarms implement the "best-of-N" decision rule? Behavioral Ecology and Sociobiology, 49, 416-427.

Selten, R. (2001). What is bounded rationality? In G. Gigerenzer \& R. Selten (Eds.), Bounded rationality (pp. 13-36). Cambridge, MA: MIT Press.

Shephard, R. N. (2001). On the possibility of universal mental laws: A reply to my critics. Behavioral and Brain Sciences, 24, 712-748.

Simon, H. A. (1955). A behavioral model of rational choice. Quarterly Journal of Economics, 69, 99-118.

Simon, H. A. (1956). Rational choice and the structure of environments. Psychological Review, 63, 129-138.

Snow, R. E. (1994). A person-situation interaction theory of intelligence in outline. In A. Demetriou \& A. Efklides (Eds.), Intelligence, mind, and reasoning: Structure and development (pp. 11-28). Amsterdam: North-Holland.

Sternberg, R. J. (1999). Intelligence as developing expertise. Contemporary Educational Psychology, 24, 359-375.

Sternberg, R. J., \& Kaufman, J. C. (Eds.). (2002). The evolution of intelligence. Mahwah, NJ: Erlbaum.

Sternberg, R. J., Grigorenko, E. L., \& Bundy, D. A. (2001). The predictive value of IQ. Merrill-Palmer Quarterly, 47, 1-41.

Wang, Y., \& Frost, B. J. (1992). Time to collision is signaled by neurons in the nucleus rotundus of pigeons. Nature, 356, 236-238.

Williams, G. C. (1996). Adaptation and natural selection. Princeton, NJ: Princeton University Press. 